\title{
Ventilation and perfusion lung scintigraphy of allergen-induced airway responses in atopic asthmatic subjects
}

\author{
Krishnan Parameswaran MBBS MD PhD FRCP ${ }^{1,2}$, Andrew C Knight MSc MIPEM ${ }^{3}$, \\ Niall P Keaney MBChB PhD FRCP ${ }^{1}$, E David Williams PhD FIPEM ${ }^{3}$, Ian K Taylor MBBS FRCP ${ }^{1}$
}

K Parameswaran, AC Knight, NP Keaney, ED Williams, IK Taylor. Ventilation and perfusion lung scintigraphy of allergen-induced airway responses in atopic asthmatic subjects. Can Respir J 2007;14(5):285-291.

BACKGROUND: Both ventilation (V) and perfusion (Q) of the lungs are altered in asthma, but their relationships with allergeninduced airway responses and gas exchange are not well described. METHODS: The effects of aerosolized allergen provocation of V/Q abnormalities in nonsmoking, male atopic asthmatics (six dual responders and two isolated early responders) were compared with measurements of airflow limitation (forced expiratory volume in $1 \mathrm{~s}$ $\left[\mathrm{FEV}_{1}\right]$ ), gas exchange (arterial oxygen saturation, arterial oxygen partial pressure and alveolar-arterial oxygen gradient) and airway reactivity (provocative concentration of histamine causing a decrease of $20 \%$ in $\mathrm{FEV}_{1}$ ). $\mathrm{V}$ and Q lung scans at 30 min and $6 \mathrm{~h}$ following allergen challenge and changes in all variables were compared with prechallenge data. Digital image data were registered to baseline scans, and quantitative comparisons of changes made were supported by qualitative assessments of the images.

RESULTS: All subjects showed evidence of impaired gas exchange, as reflected by lowered arterial oxygen tension and widened alveolar arterial oxygen gradients. Baseline V/Q scans were abnormal, and there were allergen-induced changes in $\mathrm{V}$ and $\mathrm{Q}$ at $30 \mathrm{~min}$, with scans at $6 \mathrm{~h}$ showing additional changes in $\mathrm{Q}$, particularly in dual responders. Allergen-induced gas trapping was evident at $30 \mathrm{~min}$ and was sustained at $6 \mathrm{~h}$.

CONCLUSIONS: Regional patterns of $\mathrm{V}$ and $\mathrm{Q}$ derived from lung scintigraphy showed a wider range of disturbances than were indicated by the magnitude of airflow limitation and arterial hypoxemia following allergen provocation, and they remained abnormal despite normalization of $\mathrm{FEV}_{1}$. Imaging of regional abnormalities of gas exchange may be relevant in the evaluation of patients with asthma.

Key Words: Airway responses; Allergen inhalation; Asthma; Gas exchange; Lung scintigraphy

A wide variety of lung scan abnormalities, affecting both ventilation (V) and perfusion (Q), have been described in both spontaneous and induced asthma (1-11). Previous studies $(12,13)$ of experimentally provoked asthma in animal models suggest that widespread peripheral airway edema and mucus plugging, rather than bronchoconstriction, form the pathological basis of gas exchange abnormalities in acute asthma. V/Q abnormalities are considered to be pivotal factors modulating arterial hypoxemia. Gas exchange impairments
La scintigraphie pulmonaire de ventilation et perfusion des réponses des voies aériennes induites par des allergènes chez des sujets asthmatiques atopiques

HISTORIQUE : Tant la ventilation (V) que la perfusion (Q) des poumons sont modifiées en présence d'asthme, mais leur lien avec les réponses des voies aériennes induites par des allergènes et les échanges gazeux n'est pas bien décrit.

MÉTHODOLOGIE : Les effets d'une provocation par aérosol d'allergènes sur les anomalies de V/Q d'asthmatiques non fumeurs atopiques de sexe masculin (six doubles répondants et deux répondants isolés précoces) ont été comparés aux mesures de limitation du débit d'air (volume expiratoire maximal par seconde [VEMS]), aux échanges gazeux (saturation d'oxygène artériel, pression partielle de l'oxygène artériel et gradient d'oxygène alvéolaire artériel) et à la réactivité des voies aériennes (concentration provocatrice d'histamine responsable d'une diminution de la VEMS de $20 \%$ ). On a comparé les scintigraphies pulmonaires de V/Q 30 minutes et six heures après le test de provocation par allergènes et les modifications à toutes les variables aux données avant le test. Les images numérisées ont été inscrites dans les scintigraphies de départ, et les comparaisons quantitatives des modifications étaient étayées par des évaluations qualitatives des images. RÉSULTATS : Tous les sujets présentaient des traces de perturbation des échanges gazeux, reflétée par une diminution de la tension de l'oxygène artériel et un élargissement des gradients d'oxygène alvéolaire artériel. Les scintigraphies de V/Q de départ étaient anormales, et on remarquait des modifications à la $V$ et à la $Q$ induites par les allergènes au bout de $30 \mathrm{mi}$ nutes, les scintigraphies au bout de six heures révélant d'autres modifications de la $\mathrm{Q}$, notamment chez les répondants doubles. Le blocage des gaz induit par les allergènes était évident à 30 minutes, et se maintenait à six heures. CONCLUSIONS : Des modèles régionaux de la $V$ et de la $Q$ dérivés de la scintigraphie pulmonaire ont révélé une plus vaste gamme de perturbations que le supposait la magnitude de la limitation du débit d'air et l'hypoxémie artérielle après une provocation par allergènes, et ces perturbations sont demeurées anormales malgré la normalisation de la VEMS. L'imagerie des anomalies régionales des échanges gazeux pourrait contribuer à l'évaluation des patients asthmatiques.

${ }^{1}$ Department of Respiratory Medicine, Sunderland Royal Hospital, Sunderland, United Kingdom; ${ }^{2}$ Department of Medicine, McMaster University, Hamilton, Ontario; ${ }^{3}$ Regional Medical Physics Department, Sunderland Royal Hospital, Sunderland, United Kingdom

Correspondence: Dr Krishnan Parameswaran, Firestone Institute for Respiratory Health, St Joseph's Healthcare, 50 Charlton Avenue East,

Hamilton, Ontario L8N 4A6. Telephone 905-522-1155 ext 35044, fax 905-521-6183, e-mail parames@mcmaster.ca 
TABLE 1

Details of the patients' spirometry, treatment and allergen doses

\begin{tabular}{|c|c|c|c|c|c|c|c|c|}
\hline Patient & $\begin{array}{c}\text { Age } \\
\text { (years) }\end{array}$ & $\begin{array}{c}\text { Disease } \\
\text { duration (years) }\end{array}$ & $\begin{array}{l}\mathrm{FEV}_{1} \\
\text { (L) }\end{array}$ & $\begin{array}{c}\mathrm{FEV}_{1} \\
\text { (\% predicted) }\end{array}$ & $\begin{array}{c}\mathrm{PC}_{20} \text { histamine } \\
(\mathrm{mg} / \mathrm{mL})\end{array}$ & $\begin{array}{l}\text { Mean daily inhaled } \\
\text { steroid dose }(\mu \mathrm{g})\end{array}$ & $\begin{array}{c}\text { Cumulative allergen } \\
\text { dose (U) }\end{array}$ & $\begin{array}{c}\text { Airway } \\
\text { response }\end{array}$ \\
\hline 1 & 30 & 18 & 3.48 & 76 & 1.70 & $\mathrm{FP}(2000)$ & $\mathrm{GP}(31,000)$ & IER \\
\hline 2 & 39 & 12 & 2.95 & 78 & 0.80 & BDP (400) & GP (1000) & DR \\
\hline 4 & 33 & 7 & 2.97 & 75 & 1.16 & BDP $(2000)$ & $\operatorname{GP}(31,000)$ & DR \\
\hline 5 & 35 & 25 & 3.28 & 80 & 0.45 & BUD (2000) & $\operatorname{GP}(31,000)$ & $\mathrm{DR}$ \\
\hline 8 & 28 & 25 & 3.00 & 69 & 0.81 & None & HDM (6000) & DR \\
\hline
\end{tabular}

BDP Beclomethasone dipropionate; BUD Budesonide; DR Dual response; FEV 1 Forced expiratory volume in 1 s; FP Fluticasone propionate; GP Grass pollen; HDM House dust mite or Dermatophagoides pteronyssinus; IER Isolated early response; $P C_{20}$ histamine Provocative concentration of histamine causing a decrease of greater than $20 \%$ in FEV 1

abnormalities (15) and failure to obtain objective data on asthma severity at the time of scanning $(5,16)$.

Our aim was to develop methods for computer analysis of lung scans, which may be applied to quantify $\mathrm{V}$ and $\mathrm{Q}$ abnormalities, as well as to assess airway physiology and inflammation during the biphasic asthmatic response. Disparities between spirometric assessments of large airway function and tests that reflect gas exchange abnormalities may indicate the different mechanisms involved in early and late asthmatic responses. The present study in mild atopic asthmatic subjects was intended to determine the temporal abnormalities in gas exchange, as well as airway physiology and reactivity, following aerosolized allergen challenge, and to relate these to regional disturbances in lung $\mathrm{V}$ and $\mathrm{Q}$.

\section{PATIENTS AND METHODS}

\section{Subjects}

Eight nonsmoking, male patients with mild to moderate asthma, aged 30 to 65 years (forced expiratory volume in $1 \mathrm{~s}\left[\mathrm{FEV}_{1}\right]$ between $66 \%$ and $99 \%$ of predicted value), participated in the present study after giving written and informed consent. Approval was obtained from the Local Research Ethics Committee of the Sunderland Health Authority (United Kingdom) and the Administration of Radioactive Substances Advisory Committee (United Kingdom Department of Health, United Kingdom). All patients were atopic, as defined by skin prick test positivity to at least two aeroallergens, and had a history of self-reported nasobronchial allergy. All had documented reversibility (greater than $20 \%$ ) in either $\mathrm{FEV}_{1}$ or peak expiratory flow, either spontaneously or with treatment. All were clinically stable at the time of the study, with no evidence of either upper or lower respiratory tract infection and no recent hospital admission caused by acute exacerbations of asthma. The patients' current medications included varying dosage requirements of inhaled corticosteroids (depending on clinical severity) and intermittent use of the inhaled beta 2 agonist salbutamol (Table 1).

\section{Preparation of solutions}

Allergen: Lyophilized extracts of allergen, either Dermatophagoides pteronyssinus or mixed grass pollen (ALK-Abelló A/S, Denmark), were reconstituted with $4.5 \mathrm{~mL}$ of the diluent supplied to produce stock concentrations of 100,000 U/mL. Subsequent concentrations of allergen for aerosol challenge were diluted from this stock solution in $0.9 \%$ saline on the morning of the present study.
Histamine: Serial dilutions of histamine acid phosphate were used from presealed vials of the solutions (concentrations ranging from $0.3 \mathrm{mg} / \mathrm{mL}$ to $16.0 \mathrm{mg} / \mathrm{mL}$ ).

\section{Airway challenges}

Airway challenges were administered via a compressed, air-driven nebulizer attached to a breath-activated dosimeter (FrenchRosenthal, PDS Instruments, USA) with a delivery time of $1 \mathrm{~s}$. Subjects inhaled the aerosol from a mouthpiece by taking five consecutive breaths from the functional residual capacity to the total lung capacity; under these conditions, $5 \mu \mathrm{L}$ was delivered per breath. Airway calibre was assessed by a single measurement of $\mathrm{FEV}_{1}$ with a dry-wedge spirometer (Vitalograph Ltd, United Kingdom).

Histamine challenge: For the assessment of nonspecific airway hyper-responsiveness, the provocative concentration of histamine causing a decrease greater than $20 \%$ in $\mathrm{FEV}_{1}\left(\mathrm{PC}_{20}\right.$ histamine) was determined. $\mathrm{FEV}_{1}$ was measured both before and $1 \mathrm{~min}$ after five consecutive breaths of isotonic saline, with the postsaline value designated as the basal value. Doubling doses of histamine acid phosphate were then inhaled, followed by $\mathrm{FEV}_{1}$ measurements 1 min later, until the $\mathrm{FEV}_{1}$ had fallen by more than $20 \%$ from the basal value. $\mathrm{PC}_{20}$ histamine was estimated by linear interpolation from the last two points of the dose response.

Allergen challenge: Either D pteronyssinus or grass pollen extract was chosen, depending on the patient's clinical history and which allergen produced a greater response to skin prick testing. Aerosolized allergen challenge (17) was performed after the determination of postsaline baseline $\mathrm{FEV}_{1}$ (always within $10 \%$ of the presaline value). The initial dose of allergen $(1000 \mathrm{U} / \mathrm{mL}$ in all subjects) was inhaled with a nose clip, and $\mathrm{FEV}_{1}$ was measured 10 min later. If the $\mathrm{FEV}_{1}$ had fallen by less than $10 \%$ of the postsaline baseline, the allergen concentration was increased fivefold; if the fall was between $10 \%$ and $15 \%$, the allergen concentration was increased 2.5-fold; and if the fall was more than $15 \%$, no further allergen challenge was given. After the inhalation of the last dose of allergen, postchallenge $\mathrm{FEV}_{1}$ measurements were made every $15 \mathrm{~min}$ for $2 \mathrm{~h}$, and then every $30 \mathrm{~min}$ for $4 \mathrm{~h}$, except when lung scanning was in progress. By applying the above criteria, subjects received up to three doses of allergen: five $5 \mu \mathrm{L}$ breaths of increasing allergen concentrations of $1000 \mathrm{U} / \mathrm{mL}, 5000 \mathrm{U} / \mathrm{mL}$ and finally $25,000 \mathrm{U} / \mathrm{mL}$ (units are those quoted by the manufacturer).

\section{Study design}

The study took place on two days; the screening visit (day 1) was $48 \mathrm{~h}$ before the main study day (day 2). 
TABLE 2

Study design

\begin{tabular}{|c|c|c|c|c|c|}
\hline Day 1 & Day 2 & Day 2 & Day 2 & Day 2 & Day 2 \\
\hline \multicolumn{6}{|l|}{ Time } \\
\hline $12: 00$ & 08:00 & 08:10 & $08: 40$ & $14: 40$ & $17: 00$ \\
\hline$-48 \mathrm{~h}$ & $0 \mathrm{~min}$ & $10 \mathrm{~min}$ & $30 \mathrm{~min}$ & $6 \mathrm{~h}$ & $8 \mathrm{~h}$ \\
\hline \multicolumn{6}{|l|}{ Procedures } \\
\hline $\begin{array}{l}\text { History; examination; spirometry; lung scans; } \\
\mathrm{PC}_{20} \text { histamine, } \mathrm{SaO}_{2} \text { and blood gas measurements } \\
\text { chest x-ray; electrocardiogram; skin prick tests }\end{array}$ & $\begin{array}{l}\mathrm{FEV}_{1} \text { measurement; } \\
\text { aerosol allergen } \\
\text { challenge }\end{array}$ & $\mathrm{FEV}_{1}$ measurement & $\begin{array}{l}\text { Lung scans; } \\
\mathrm{FEV}_{1}, \mathrm{SaO}_{2} \\
\text { and blood gas } \\
\text { measurements }\end{array}$ & $\begin{array}{l}\text { Lung scans; } \\
\mathrm{FEV}_{1}, \mathrm{SaO}_{2} \\
\text { blood gas and } \\
\mathrm{PC}_{20} \text { histamine } \\
\text { measurements }\end{array}$ & $\begin{array}{l}\text { Examination; } \\
\text { bronchodilator; } \\
\text { discharged } \\
\text { from hospital }\end{array}$ \\
\hline
\end{tabular}

FEV $V_{1}$ Forced expiratory volume in $1 \mathrm{~s} ; \mathrm{PC}_{20}$ histamine Provocative concentration of histamine causing a decrease of greater than $20 \%$ in $\mathrm{FEV}$; SaO $\mathrm{Arterial}_{\text {oxy- }}$ gen saturation

On day 1, the subjects attended the clinical laboratory at midday, having avoided inhaled beta ${ }_{2}$-agonist and corticosteroid therapy for $24 \mathrm{~h}$, as well as beverages containing caffeine for at least $8 \mathrm{~h}$. The subjects underwent a full clinical examination, had a chest $\mathrm{x}$-ray and 12-lead electrocardiogram recorded, and had blood gases measured in the arterial blood obtained from a radial artery puncture. The alveolar-arterial gradient for oxygen was calculated from the alveolar gas equation. Standard V and Q lung scans were then performed as described below. All the patients had their baseline lung scans performed at the same time of day. Afterwards, $\mathrm{PC}_{20}$ histamine was determined, and the patients went home after the residual bronchoconstriction had been reversed with nebulized salbutamol.

On day 2 (Table 2), the patients attended the clinical laboratory at 07:30, having witheld their steroid medications since day 1 and beta ${ }_{2}$-agonist therapy for at least $12 \mathrm{~h}$. The patients rested for 15 min before $\mathrm{FEV}_{1}$ was assessed. An aerosolized whole lung allergen challenge was then performed at 08:00, as described above, to cause a $15 \%$ fall in $\mathrm{FEV}_{1}$ from the postsaline baseline or until the maximum dose of allergen was administered. Arterial blood gas was then checked immediately, and a pulse oximeter (Ohmeda Biox 3700, BOC Health Care, United Kingdom) with a finger probe was connected to monitor the oxygen saturation continuously. The alveolar-arterial oxygen gradient was also calculated. Lung scans were then performed, after which the patient was closely monitored (including continuous oximetry) for the next $6 \mathrm{~h}$, and $\mathrm{FEV}_{1}$ was measured every $15 \mathrm{~min}$ for $2 \mathrm{~h}$ and then every one-half hour until the next scan. Arterial blood gas was sampled just before the final lung scan. After the scans, $\mathrm{PC}_{20}$ histamine was determined, as well as the shift in reactivity, expressed in doubling doses of histamine concentration.

Residual bronchoconstriction was reversed with $5 \mathrm{mg}$ of nebulized salbutamol and $2 \mathrm{mg}$ of inhaled beclomethasone dipropionate, administered via a large volume spacer device; this was repeated $4 \mathrm{~h}$ later. The patients were reviewed in the chest clinic the next morning.

\section{Lung scans}

Equipment: All images were acquired using a rectangular gamma camera (General Electric Camstar XR/T, Camstar Inc, USA) with a low energy general purpose collimator. Image data were processed and analyzed using Hermes software (Nuclear Diagnostics, United Kingdom).
V scans: Patients were seated and connected to a closed-loop breathing system. The gamma camera was positioned posteriorly, and the computer was setup to acquire a dynamic study containing three groups of 64 by 64 pixel images. Two hundred megabecquerels of xenon (Xe)-133 gas were administered orally as the patient inhaled deeply and held it for $15 \mathrm{~s}$. The patient then exhaled oxygen into the closed-loop system, while four images, each $1 \mathrm{~min}$ long, were acquired. Room air was then introduced to the system, and the exhaled gas was collected in a reservoir, while a further four $1 \mathrm{~min}$ washout images were acquired.

Q scans: Patients were in a supine position and injected intravenously with technetium ( $\mathrm{Tc}_{\mathrm{c}}$ - $-99 \mathrm{~m}$ macroaggregated albumin (MAA) through a $21 \mathrm{G}$ needle. One hundred megabecquerels were used for the baseline scans. On day 2, $60 \mathrm{MBq}$ were used for the first scan and $140 \mathrm{MBq}$ for the second scan to minimize interference from the first to the second scan by residual radioactivity. An image of residual activity was obtained immediately before the second injection. The patients sat up within $30 \mathrm{~s}$ of the injections, and they were imaged while seated upright. The six standard views (posterior, left and right posterior obliques, anterior, and left and right anterior obliques) were taken, each acquiring 500,000 counts in 128 by 128 pixel format - reformatted to 64 by 64 for analysis. Analysis of lung scans: Quantitative approaches were used to compare the postchallenge lung scan with the baseline lung scan. For these quantitative analyses, only the posterior view was used; it is generally accepted as the most useful single view because it shows the largest proportion of lung segments. A 64 by 64 data matrix was selected to retain good positional information while maximizing counts per pixel, thus reducing the 'noise' level. To quantify changes, it was first necessary to 'register' each postchallenge scan to the position of the corresponding baseline scan. Registration was achieved using the iterative simplex minimization method, with count difference as a measure of image similarity (Hermes Multimodality Software Version 3.0, Nuclear Diagnostics, United Kingdom [18]), which moves the image data within the matrix. The result of registration was that each pixel location in each image matrix corresponded to the same physical location. Quantitative comparisons between the data in each pixel of each sequential image for the same patient could therefore be made directly.

For the $6 \mathrm{~h} \mathrm{Q}$ scan, a correction was made for residual radioactivity from the previous scan on the same day by registering the scans and then subtracting the image data of residual activity from the $6 \mathrm{~h}$ image data. This correction was approximately $9 \%$ of the 


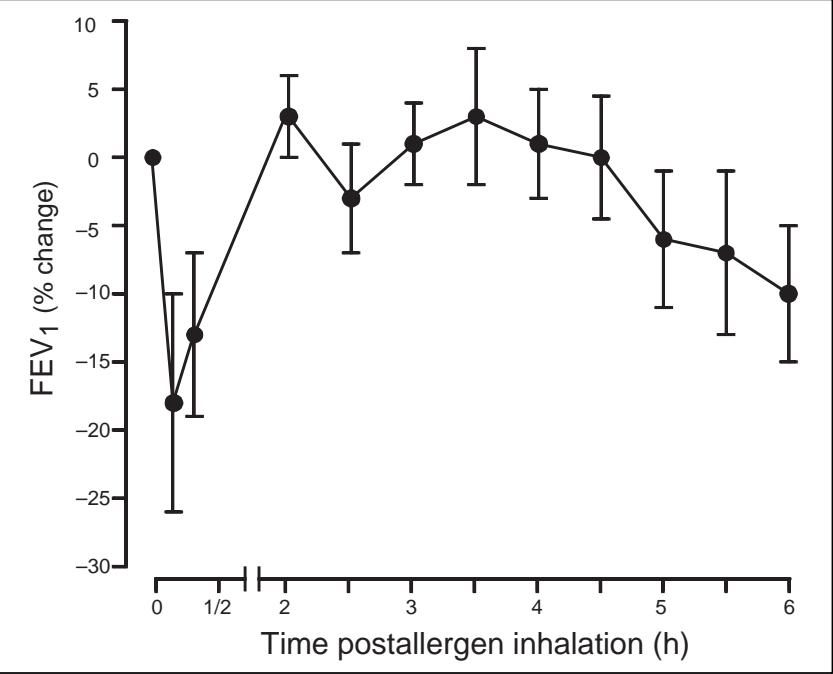

Figure 1) Bronchoconstrictor responses to allergen challenge, expressed as the percentage of baseline forced expiratory volume in $1 \mathrm{~s}$ $\left(F E V_{1}\right)$. Six of the eight subjects showed early and late asthma responses

counts in the $6 \mathrm{~h}$ image: higher than expected from published data on Tc-99m MAA kinetics (19).

For comparison with the baseline scan, each postchallenge scan (ie, at $30 \mathrm{~min}$ and at $6 \mathrm{~h}$ ) was 'normalized' to the baseline scan. Normalization was the process used to correct for differences in the total amount of radioactivity in the patient's lungs at each scan. The total number of counts in each image was taken to be proportional to the amount of radioactivity present. In the following, total counts in baseline scans are denoted $\mathrm{Tb}$, while total counts in a postchallenge scan are denoted $\mathrm{Tp}$; the corresponding typical individual pixel counts in each scan are denoted $\mathrm{Cb}$ and $\mathrm{Cp}$.

The normalization correction factor $(\mathrm{R})$ was therefore the ratio of the total number of counts in the scan to the total number in the baseline scan.

$$
\mathrm{R}=\mathrm{Tp} / \mathrm{Tb}
$$

The counts in each pixel in each postchallenge scan were divided by the normalization ratio to provide the required corrected counts ( $\mathrm{Cp}$, corrected).

$$
\mathrm{Cp}, \text { corrected }=\mathrm{Cp} / \mathrm{R}
$$

The next step was to quantify the change between each postchallenge scan and the baseline scan. This was done by calculating the difference (D) between the counts in each corresponding pixel in the postchallenge and the baseline scans.

$$
\mathrm{D}=\mathrm{Cp} \text {, corrected }-\mathrm{Cb}
$$

These calculated values were displayed as a 'count difference' image and recorded on film. Some of these differences were positive, ie, with more counts in the postchallenge scan, and some were negative, ie, with fewer counts in the postchallenge scan. To obtain a figure expressing the overall magnitude of the postchallenge change from baseline, the sum of all these differences for all the pixels in a scan was calculated, disregarding whether the differences were positive or negative. This sum was then expressed as a percentage of the total number of counts in the baseline image and was termed the 'percentage difference from baseline'.

This procedure was applied to both $\mathrm{V}$ and $\mathrm{Q}$ scans, comparing the 30 min and $6 \mathrm{~h}$ scans with baseline. For the $\mathrm{V}$ scans, the initial

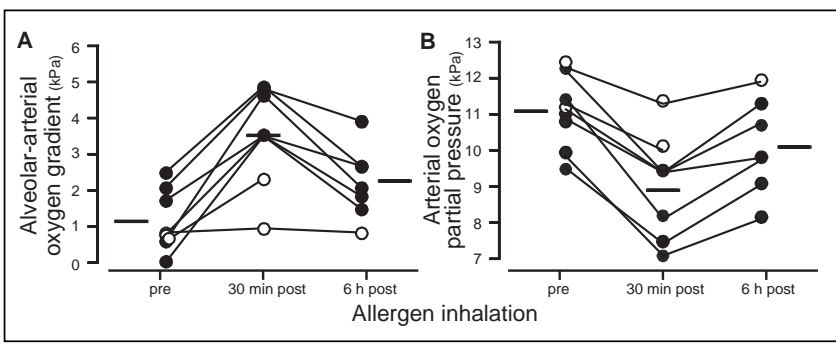

Figure 2) The early and late allergen-induced changes in (A) the alveolar-arterial oxygen gradient and (B) arterial oxygen partial pressure. The open circles represent patients with an isolated early response. $1 \mathrm{kPa}=7.5 \mathrm{mmHg}$

breath-holding image data were used, because these provide the best single estimate of regional lung $\mathrm{V}$. To provide a quantitative measure of retention in the lungs during the washout phase, the number of counts in the fourth minute of washout was expressed as a percentage of the number in the fourth minute of rebreathing (which is related to lung volume). In normal subjects, there is negligible retention after 4 min.

To help in assessing the significance of the pixel count difference analysis, repeated posterior view $Q$ lung scans were obtained from controls (three patients undergoing routine diagnostic lung scanning), and these were registered and analyzed as described above. The pixel count differences on these repeated scans, corresponding to what was expected to be no significant change, were $6 \%, 7 \%$ and $8 \%$. Any difference greater than $8 \%$ was therefore regarded as a significant change.

Support for the validity of the difference in images was obtained from visual assessments of images made by an experienced reader of nuclear medicine images. First, the postchallenge scans were classified on a simple ordinal scale ( 0 to 3 ) showing small or gross changes from baseline. These scores were compared (Spearman's rank correlation) with the following percentage differences: $r=0.65$ and $\mathrm{P}=0.007$ for $\mathrm{Q}$ scans; and $\mathrm{r}=0.76$ and $\mathrm{P}=0.0006$ for $\mathrm{V}$ scans. The count difference images were then placed in rank order of increasing apparent extent of the difference. The resulting order correlated well with the calculated percentage differences: $r=0.92$ and $\mathrm{P}<0.0001$ for the $\mathrm{Q}$ scans; $\mathrm{r}=0.56$ and $\mathrm{P}=0.02$ for the $\mathrm{V}$ scans.

\section{Statistical analysis}

Comparisons of $\mathrm{Q}, \mathrm{V}$, and retention and gas exchange, between different time points, were made by repeated measures ANOVA with Bonferroni adjustment for multiple comparisons. Probabilities are quoted for pairwise comparisons. $\mathrm{P}<0.05$ was considered statistically significant.

\section{RESULTS}

The allergen-invoked bronchoconstriction showed both early and late response phases in six subjects; the other two subjects showed an isolated early response (Figure 1). The mean \pm SEM value of the maximum decrease in $\mathrm{FEV}_{1}$ (relative to baseline) during the early phase was $16 \pm 7.5 \%$ and in the late phase was $14 \pm 4.5 \%$. The median doubling dose shift in $\mathrm{PC}_{20}$ histamine reactivity following allergen inhalation was 1.48 .

All patients showed evidence of impaired gas exchange as reflected by lowered arterial oxygen tension and widened alveolar-arterial oxygen gradients. The allergen-invoked changes in the alveolar-arterial gradient are shown in 


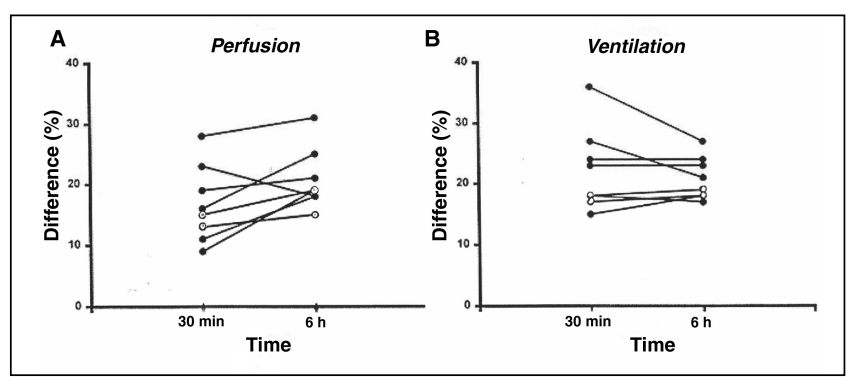

Figure 3) The percentage differences from baseline scans for perfusion (A) and ventilation (B) at $30 \mathrm{~min}$ and $6 \mathrm{~h}$ after allergen challenge. The open circles represent patients with isolated early response

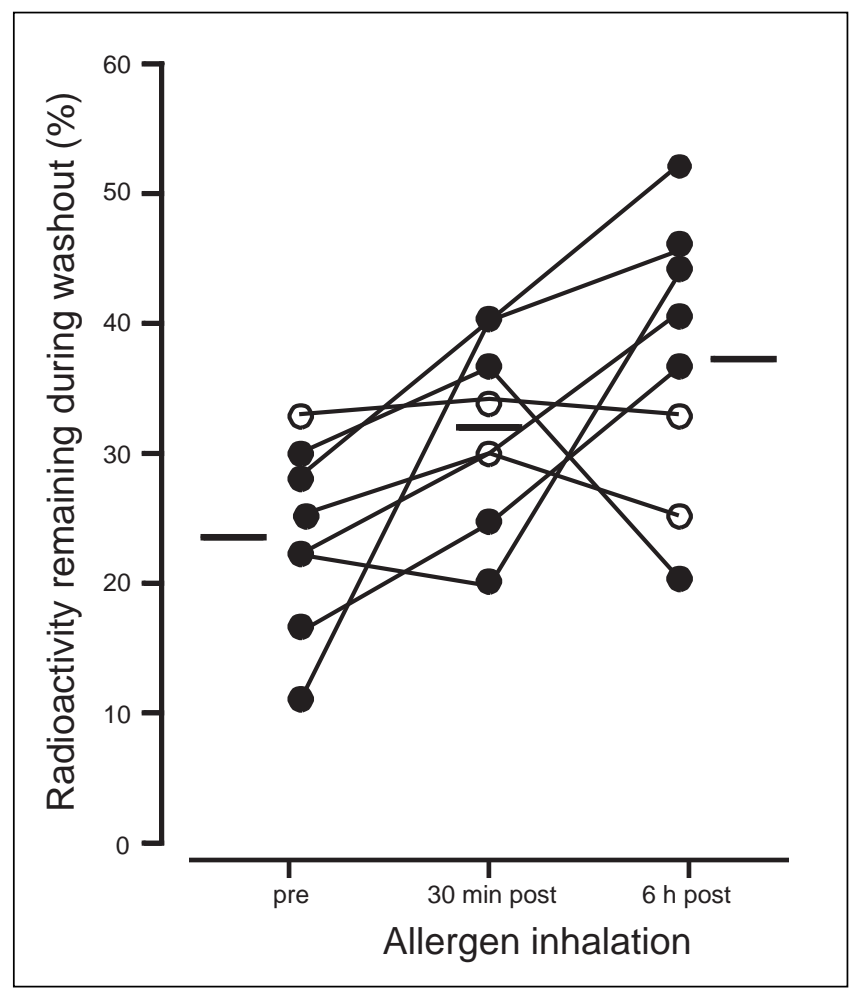

Figure 4) Retention of xenon-133 in the lungs before and after allergen challenge. The open circles represent patients with an isolated early response

Figure 2A. The change from preallergen baseline values was significant at $30 \mathrm{~min}(\mathrm{P}=0.002)$ and at $6 \mathrm{~h}(\mathrm{P}=0.04)$. There was no significant change in the gradient from $30 \mathrm{~min}$ to $6 \mathrm{~h}$ $(\mathrm{P}=0.06)$. A qualitatively similar pattern is reflected by inverse changes in the arterial oxygen partial pressure data (Figure 2B), but with significant changes from baseline to $30 \mathrm{~min}(\mathrm{P}=0.001)$ and from $30 \mathrm{~min}$ to $6 \mathrm{~h}(\mathrm{P}=0.004)$, although not at $6 \mathrm{~h}$ relative to baseline $(\mathrm{P}=0.1)$.

Some abnormalities in $\mathrm{V}$ and $\mathrm{Q}$ were observed in all baseline scans. There were allergen-induced quantitative changes from baseline in both $\mathrm{V}$ and $\mathrm{Q}$, which could all be considered significant because they were larger than the control data for repeated scans (Figure 3). The changes from baseline in $\mathrm{Q}$ at $6 \mathrm{~h}$ (mean $21 \pm 2 \%$ ) were larger than those at $30 \mathrm{~min}$ (mean $17 \pm 2 \%$ ), whereas the changes in $\mathrm{V}$ were similar at $30 \mathrm{~min}$ (mean $22 \pm 2 \%$ ) and $6 \mathrm{~h}$ (mean $20 \pm 1 \%$ ). All changes from

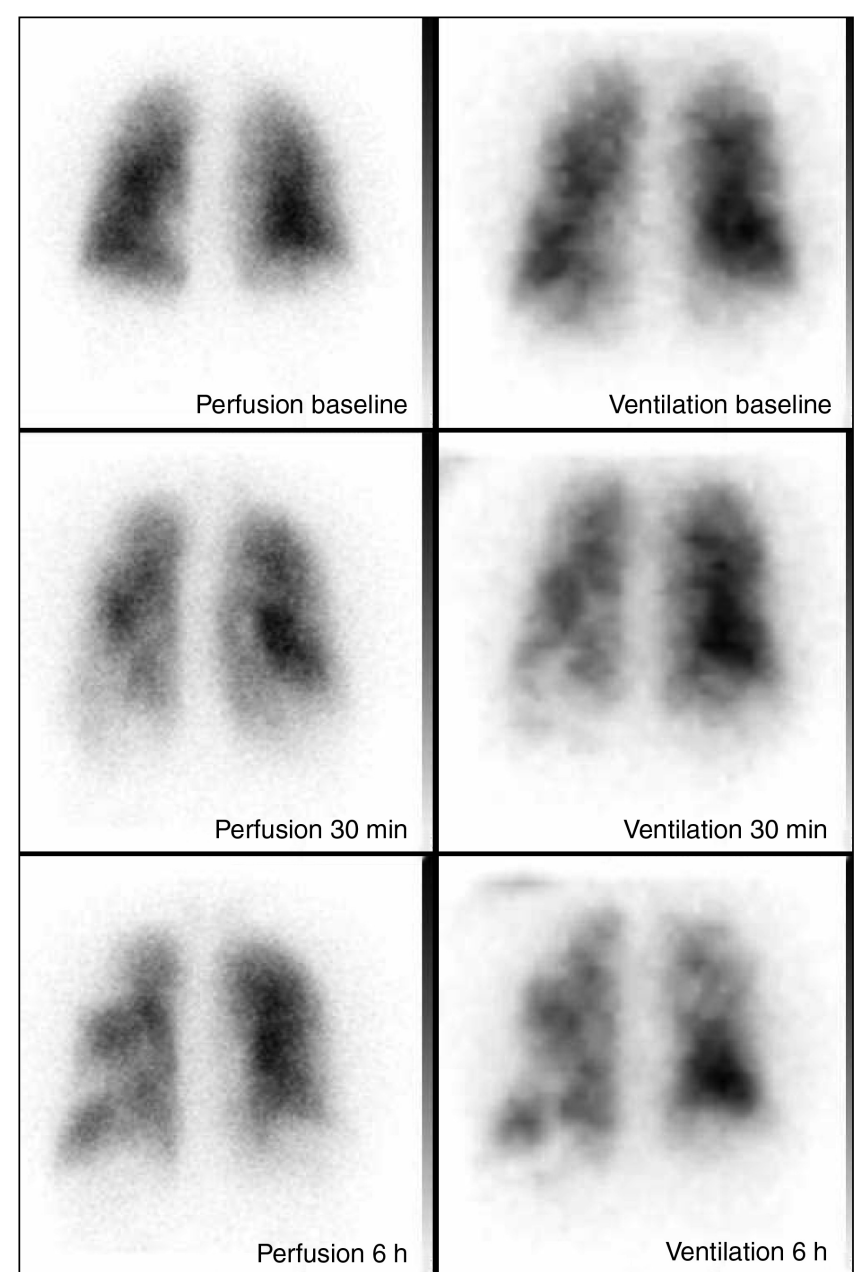

Figure 5) Lung perfusion and ventilation scan at baseline, and $30 \mathrm{~min}$ and $6 \mathrm{~h}$ after allergen inhalation in a subject with dual asthma response

baseline were significant $(\mathrm{P}<0.001)$ by the paired $t$ test. There was evidence of gas trapping from the retention of Xe-133, which continued or increased in most of the patients long after the challenge (Figure 4). Thus, retention was significantly greater at 30 min compared with baseline $(\mathrm{P}=0.02)$ and was significantly further increased at $6 \mathrm{~h}(\mathrm{P}=0.04)$. A V and $\mathrm{Q}$ scan from a patient who had a dual response is shown in Figure 5.

The relationships between allergen-invoked bronchoconstriction and the quantitative parameters of $\mathrm{V}$ and $\mathrm{Q}$ changes (per cent difference) were examined using Pearson's correlation. Early and late decreases in $\mathrm{FEV}_{1}$ were only modestly associated with respective increasing changes both in $\mathrm{V}$ scans at 30 min $(r=0.43 ; P=0.04)$ and $6 \mathrm{~h}(\mathrm{r}=0.4 ; \mathrm{P}=0.01)$, and in $\mathrm{Q}$ scans at $30 \mathrm{~min}(\mathrm{r}=0.32 ; \mathrm{P}=0.03)$ but not at $6 \mathrm{~h}$. There were no significant relationships between these $\mathrm{V}$ and $\mathrm{Q}$ changes and percentage changes from baseline in the alveolar-arterial oxygen gradient measured at the same time.

\section{DISCUSSION}

Our study illustrates that V/Q mismatching provides different and additional information to that obtained through spirometric measurements and blood gas analysis, under conditions similar to spontaneous acute asthma. Consequently, our results support the speculation that spirometric variables and V/Q 
inequality indicate different pathophysiological phenomena in asthma $(20,21)$. This suggests that disparities in $\mathrm{V}$ and $\mathrm{Q}$ in the lungs may provide additional functional assessment of allergen-induced responses, and that spirometry and arterial blood gas tension analysis alone may not suffice.

A purely visual analysis of $\mathrm{V}$ and $\mathrm{Q}$ images may be considered too subjective. Earlier attempts at quantitative analysis of changes in scans had the problem of choosing suitable reference data for the comparisons required, as well as the additional potential for masking changes resulting from the reduction of data into a one-dimensional analysis (15). The registration technique we employed removed some of the subjectivity in aligning repeated scans. The pixel level quantitative analysis should have provided greater sensitivity to change than the earlier technique (15), because it can detect changes in much smaller image elements and in two dimensions. The 'difference' images appear to provide an indication of the location and extent of provocation-induced changes, as well as a quantitative measure. Confidence in the latter was increased by the agreement found between quantitative measures and the more established visual assessment. The V/Q difference images have also given new insight into their variability, both between patients and over time. This may reflect variability and alterations in the sites of airway narrowing. One point to note in this context is the possibility that the substantial duration of disease may explain the abnormal patterns seen on the baseline studies. A potential drawback of the method employed, in addition to the limitation of image resolution, is the radiation exposure to the subjects. Each subject was given a total of $300 \mathrm{MBq}$ of Tc-99m MAA (an effective radiation dose of $3 \mathrm{mSv}$ ) and a total of $600 \mathrm{MBq}$ of Xe-133 (an effective radiation dose of $0.6 \mathrm{mSv}$ ). Although the total dose is comparable with that involved in other commonly performed nuclear medicine procedures, such as a bone scan, this is considered to have an intermediate level of risk by the Radioactive Substance Advisory Committee. Other lung imaging technologies using single photon emission computed tomography, positron emission tomography, hyperpolarized gas imaging and magnetic resonance imaging may provide more precise information, with less radiation exposure, on regional V/Q imbalances in spontaneous and induced bronchoconstriction (22).

Airway inflammation is a fundamental feature of asthma, underlying the various physiological abnormalities associated with an asthmatic attack $(23,24)$. Impairment in gas exchange and consequent hypoxia has been investigated widely by the use of the multiple inert gas elimination technique. Inequalities in $\mathrm{V}$ and $\mathrm{Q}$, which play a central role in hypoxia, have also been studied by other lung imaging techniques $(5,15)$ that have been employed to visualise allergen-invoked airway inflammation $(7,25)$. With a better understanding of the inflammatory mediators (26) involved in the pathophysiology of asthma, early and late asthmatic responses are clearly recognized (16). However, attempts to correlate lung scan abnormalities with the dynamic sequence of an asthmatic attack have been few (9-11), partly because of difficulties with the quantification of lung scan abnormalities (27) and partly because of failure to obtain objective physiological data at the time of scanning. Although some of these problems were addressed in the present study, other factors, such as nontidal breath before $\mathrm{V}$ scan and supine position for the $\mathrm{Q}$ scan, may have affected the interpretation of the results. The present study, despite these physiological and methodological limitations, showed the history of pulmonary gas exchange and spirometric variables, as well as rather different and changing patterns of $\mathrm{V}$ and $\mathrm{Q}$ imbalance throughout the recovery period of an induced asthmatic attack. $\mathrm{V}$ and $\mathrm{Q}$ patterns were observed to change independently, and although there were modest associations with some 'conventional' lung function measurements, there was no association with others. The greater change at $6 \mathrm{~h}$ from baseline in $\mathrm{Q}$ compared with $\mathrm{V}$ raises the possibility of hypoxia-induced regional vasoconstriction, which may take longer to normalize. The magnitude of gas trapping was more marked in subjects who had a dual response than in subjects who had an isolated early response, suggesting that the inflammatory response associated with the late response contributed to reducing gas emptying or airtrapping in these subjects.

The present study was designed as a pilot study for examining methods and results. The allergen challenge protocol and the subject population in the present study might have affected the magnitude of the allergen-induced airway responses and V/Q mismatch. For example, because the dose of allergen was not predicted based on skin and airway reactivity (28), a standard dose of allergen was not delivered to all the subjects. Most of the subjects, unlike in other allergen provocation studies, were using inhaled corticosteroids for their asthma control. This might have modified the allergen-induced airway and inflammatory responses (not measured in the present study), and consequently, the segmental $\mathrm{V}$ and $\mathrm{Q}$. The findings now require more extensive and conclusive examination in a larger study, including subjects with isolated early and dual airway responses to inhaled allergen and healthy control subjects, with similar levels of allergen challenge using a standardized allergen inhalation protocol and with measurements of airway inflammation.

\section{CONCLUSIONS}

The present study demonstrates the dissociation between V/Q abnormalities and tests of airflow limitation and gas exchange in allergen-provoked asthma. Such evidence may have relevance in the assessment of asthmatic attacks as well as in the evaluation of therapeutic interventions with disease-modifying effects.

ACKNOWLEDGEMENTS: The authors wish to acknowledge the contributions of the Medical Physics Unit technologists (Mike Bewick, Lisa Welsh, Kim Williams, Vicky Robson and Leanne Cunningham) who performed the scans, the assistance of S Thornell and the cooperation of Dr D Rankin. The authors also wish to thank Professors Paul O'Byrne and Myrna Dolovich, McMaster University, for their helpful comments.

Dr Krishnan Parameswaran is supported by a Canada Research Chair in Airway Regulation and Inflammation. The study was funded by research grants of the Department of Respiratory Medicine of City Hospitals Sunderland NHS Foundation Trust.

\section{REFERENCES}

1. Wagner PD, Dantzker DR, Iacovoni VE, Tomlin WC, West JB. Ventilation-perfusion inequality in asymptomatic asthma. Am Rev Respir Dis 1978;118:511-24.

2. Fazio F, Palla A, Santolicandro A, Solfanelli S, Fornai E, Giuntini C. Studies of regional ventilation in asthma using $81 \mathrm{~m}-\mathrm{Kr}$. Lung 1979;156:185-94.

3. Agnew JE, Bateman JR, Pavia D, Clarke SW. Radionuclide demonstration of ventilatory abnormalities in mild asthma. Clin Sci (Lond) 1984;66:525-31. 
4. Orphanidou D, Hughes JM, Myers MJ, Al-Suhali AR, Henderson B. Tomography of regional ventilation and perfusion using krypton $81 \mathrm{~m}$ in normal subjects and asthmatic subjects. Thorax 1986;41:542-51.

5. Vernon P, Burton GH, Seed WA. Lung scan abnormalities in asthma and their correlation with lung function. Eur J Nucl Med 1986;12:16-20.

6. Roca J, Ramis L, Rodriguez-Roisin R, Ballester E, Montserrat JM, Wagner PD. Serial relationships between ventilation-perfusion inequality and spirometry in acute asthma requiring hospitalization. Am Rev Respir Dis 1988;137:1055-61.

7. Rodriguez-Roisin R, Ferrer A, Navajas D, Augusti AG, Wagner PD, Roca J. Ventilation-perfusion mismatch after methacholine challenge in patients with mild bronchial asthma. Am Rev Respir Dis 1991;144:88-94.

8. Whyte KF, Ip M, Kirby T, Wathen CG, Flenley DC. Changes in regional ventilation during histamine bronchial challenge in stable asthma. Respiration 1994;61:68-73.

9. Munkner T, Bundgaard A. Regional V/Q changes in asthmatics after histamine inhalation. Eur J Respir Dis Suppl 1986;143:22-7.

10. Munkner T, Bundgaard A. Regional V/Q changes in asthmatics after antigen inhalation. Eur J Respir Dis Suppl 1986;143:44-7.

11. Munkner T, Bundgaard A. Regional V/Q changes in asthmatics after exercise. Eur J Respir Dis Suppl 1986;143:62-6.

12. Wagner PD, Ramsdell JW, Incavdo GA, Rubinfeldt AR, Young IH. Gas exchange following bronchial challenge with antigen in patients with extrinsic asthma. Am Rev Respir Dis 1978;117:A409.

13. Rubinfield AR, Wagner PD, West JB. Gas exchange during acute experimental canine asthma. Am Rev Respir Dis 1978;118:525-36.

14. Lagerstrand L, Larsson K, Ihre E, Zetterström O, Hedenstierna G. Pulmonary gas exchange response following allergen challenge in patients with allergic asthma. Eur Respir J 1992;5:1176-83.

15. Burton GH, Vernon P, Seed WA. An automated quantitative analysis of ventilation-perfusion lung scintigrams. J Nucl Med 1984;25:564-70

16. Iikura Y, Yamada T, Akasawa A, et al. Monitoring of inflammation in relation to pathophysiology. Allergy 1993;48(17 Suppl):138-42.
17. Taylor IK, O'Shaughnessy KM, Fuller RW, Dollery CT. Effect of cysteinyl-leukotriene receptor antagonist ICI 204.219 on allergeninduced bronchoconstriction and airway hyperreactivity in atopic subjects. Lancet 1991;337:690-4.

18. Slomka PJ, Hurwitz GA, Stephenson J, Cradduck T. Automated alignment and sizing of myocardial stress and rest scans to threedimensional normal templates using an image registration algorithm. J Nucl Med 1995;36:1115-22.

19. Malone LA, Malone JF, Ennis JT. Kinetics of technetium 99m labelled macroaggregated albumin in humans. Br J Radiol 1983;56:109-12.

20. Agnew JE, Wood EJ, Sutton PP, Bateman JRM, Pavia D, Clarke SW. Krypton-81m and 5-micron radioaerosol images in asymptomatic asthma: A blind marking assessment. Eur J Nucl Med 1984;9:502-7.

21. Wagner PD, Hedenstierna G, Rodriguez-Roisin R. Gas exchange, expiratory flow obstruction and the clinical spectrum of asthma. Eur Respir J 1996;9:1278-82.

22. Dolovich M, Labiris R. Imaging drug delivery and drug responses in the lung. Proc Am Thorac Soc 2004;1:329-37.

23. Kraft M, Djukanovic R, Wilson S, Holgate ST, Martin RJ. Alveolar tissue inflammation in asthma. Am J Respir Crit Care Med 1996;154:1505-10

24. Hamid Q, Song Y, Kotsimbos TC, et al. Inflammation of small airways in asthma. J Allergy Clin Immunol 1997;100:44-51.

25. Taylor IK, Hill AA, Hayes M, et al. Imaging allergen-invoked airway inflammation in atopic asthma with [18F]-fluorodeoxyglucose and positron emission tomography. Lancet 1996;347:937-40.

26. Puchelle E, Zahm J, Bonnet N. Imaging of airway cells. Eur Respir J 1998;12:3-5.

27. Burton GH, Seed WA, Vernon P. Computer analysis of ventilationperfusion scans for detection and assessment of lung disease. Thorax 1985;40:519-25.

28. Cockcroft DW, Murdock KY, Kirby J, Hargreave F. Prediction of airway responsiveness to allergen from skin sensitivity to allergen and airway responsiveness to histamine. Am Rev Respir Dis $1987 ; 135: 264-7$ 


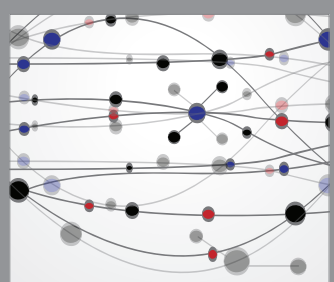

The Scientific World Journal
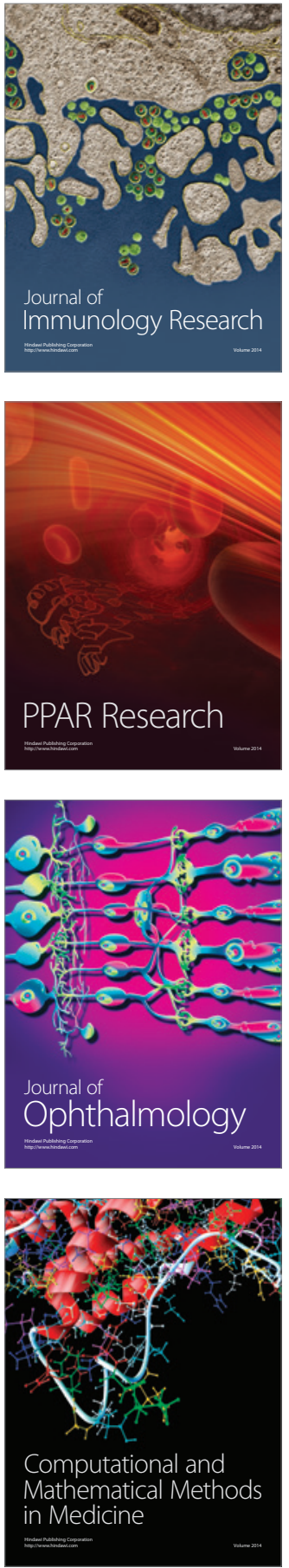

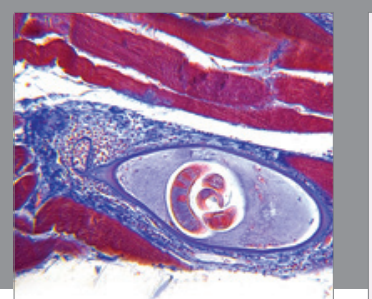

Gastroenterology Research and Practice

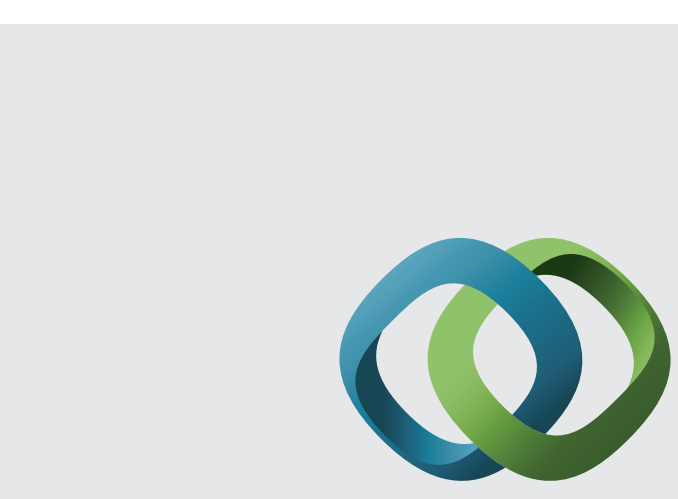

\section{Hindawi}

Submit your manuscripts at

http://www.hindawi.com
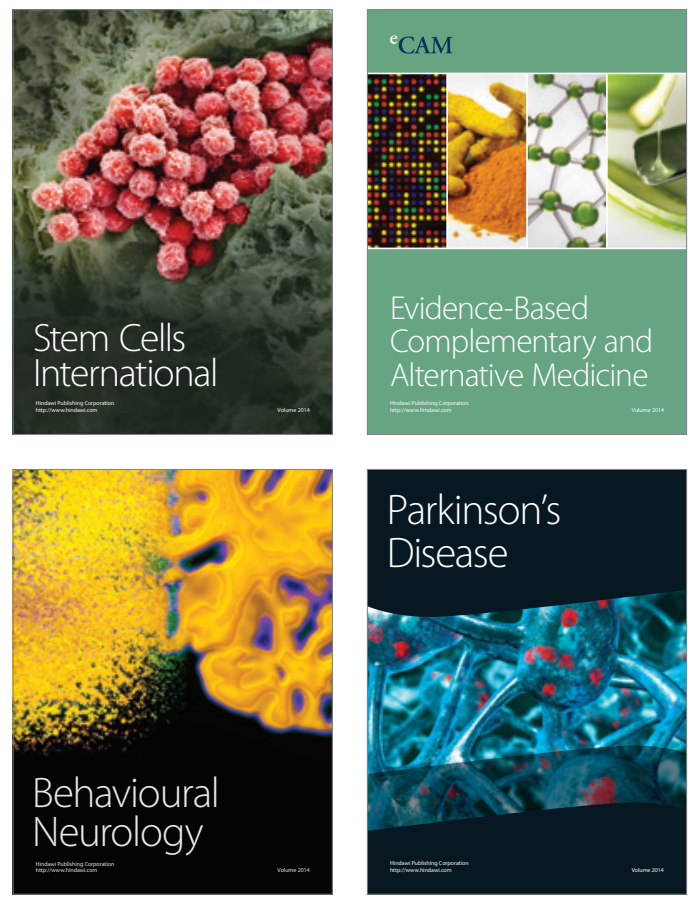
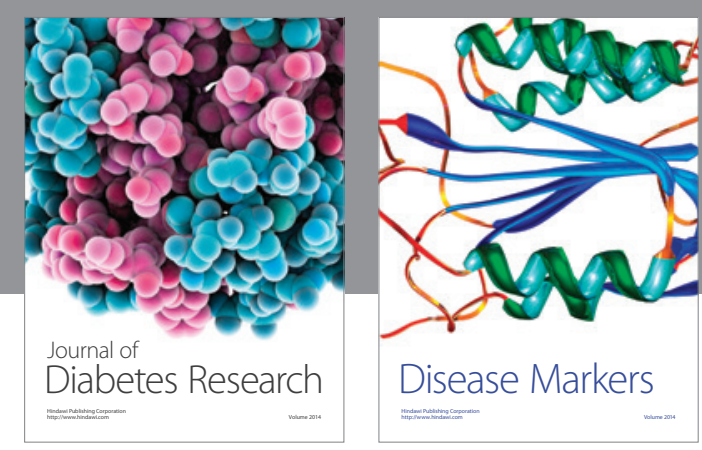

Disease Markers
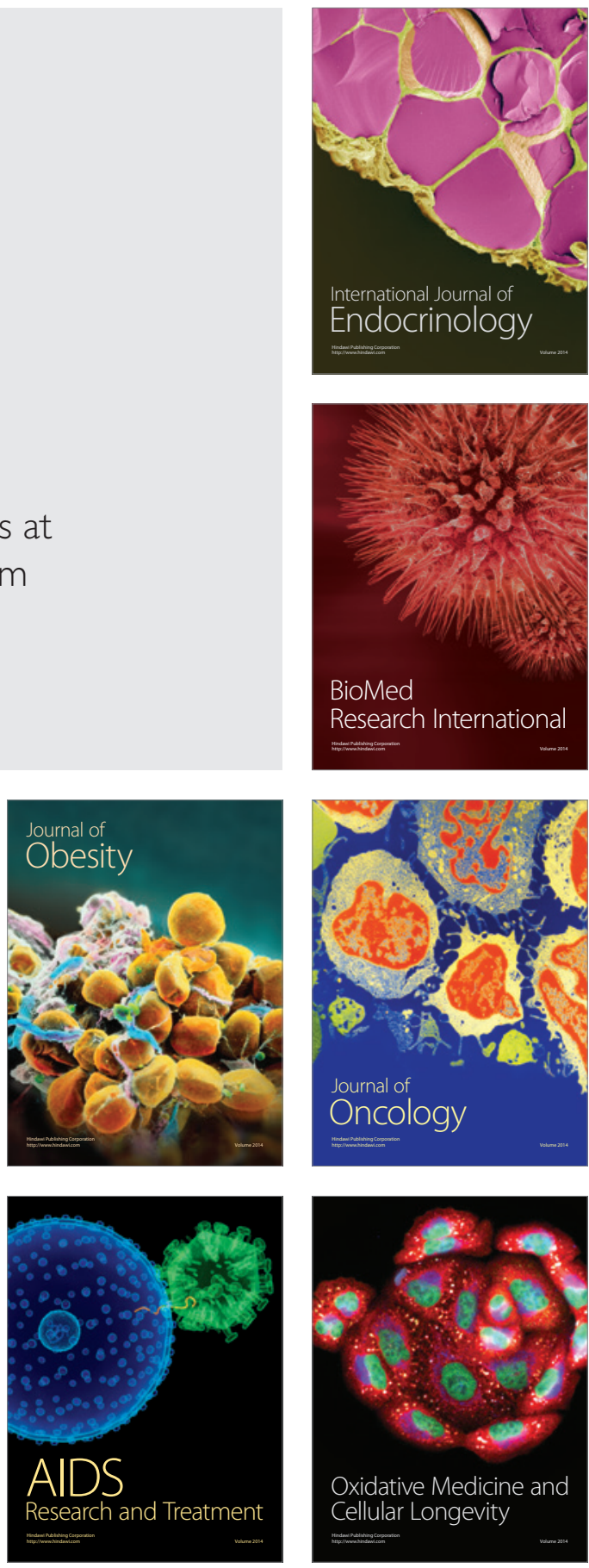